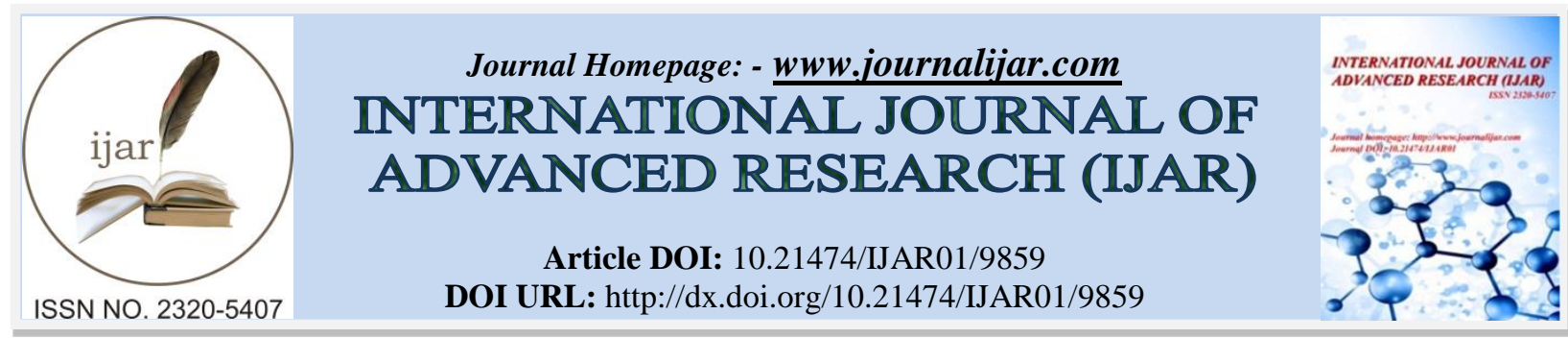

RESEARCH ARTICLE

\title{
EFFECT OF TWO-DISINFECTION TIMES ON DIMENSIONAL ACCURACY OF VINYLPOLYSILOXANE IMPRESSIONS.
}

\author{
Nawaf Alsofyniy ${ }^{1}$, Adil Almalki ${ }^{2}$, Al-Thomali Hani ${ }^{3}$ El Sayed Omar ${ }^{4}$ and Ammar Shamrani ${ }^{5}$. \\ Faculty of Dentistry, Taif University.
}

\section{Manuscript Info}

Manuscript History

Received: 08 August 2019

Final Accepted: 10 September 2019

Published: October 2019

\begin{abstract}
Purpose: To evaluate linear dimensional changes of vinylpolysilixane impressions after immersion disinfection.

Materials and Methods: A standardized steel master cast fabricated to provide dental replica of two teeth prepared for complete crown with 10-degree convergence one represent canine and other represent molar with edentulous interposed space $42.1 \mathrm{~mm}$. Auto polymerized resin perforated custom tray with $2 \mathrm{~mm}$ spacer constructed from master cast. The trays paints with adhesive, and allowed to dry for 60 seconds before obtaining the impressions. Regular body vinylpolysilixane impression material (Elite HD+ regular body zhermack) used for fabrication of 30 impressions. A 20 impressions act as control (10 of them left in atmosphere for 30,60 minutes and other 10 immersed in distilled water for 30, 60 minutes before pouring). Other 10 impressions (test group) immersed in a glutaraldehyde disinfectant solution (MD 520 impression disinfection) for 30 and 60 minutes. All impression poured with extra hard dental stone. Obtained casts evaluated for linear dimensional changes using a digital caliper. Data tabulated and statistically analyzed using one-way analysis of variance with a significance level set at $=0.05$.

Results: The highest dimensional change value was recorded after immersion impressions in distilled water for 60 minutes while, the lowest value was recorded after immersion in disinfectant solution for 60 minutes. There is no significant difference in dimensional changes between control groups and test group at both immersion times.

Conclusion: Under the limitations of present study, tasted disinfection times (30 minutes \& 60 minutes) has no effect on dimensional accuracy of tested impression material.
\end{abstract}

Copy Right, IJAR, 2019,. All rights reserved.

\section{Introduction:-}

One of the most important factors in the production of an accurate dental prosthesis is the use of a suitable impression material. There is a continuous effort to improve materials used to achieve dimensional stability precision and fine tissue details Contamination of dental impressions with oral cavity fluids including saliva and blood occurs readily in dental clinics. Mere washing of the impression does not clear away all the micro-organisms. These contaminated impressions may result in cross-infection from the patient to dentist or dental assistant or more

Corresponding Author:-Nawaf Alsofyniy.

Address:-Faculty of Dentistry, Taif University. 
importantly, laboratory technician therefor, it is necessary to adopt the disinfection of dental impressions as a mandatory procedure in dental practice. In pursuit to achieve the goal of disinfection for the protection of the dental team, it is must and necessary that accuracy and dimensional stability of impressions not be compromised. Several studies investigated the accuracy and dimensional stability of vinyl polysiloxane impression materials under different test conditions such as different levels of humidity, storage temperature and the effect of prolonged storage. The aim of our study is to evaluate linear dimensional changes of vinylpolysilixane impressions after immersion disinfection.

\section{Materials and Methods:-}

A standardized steel master cast fabricated to provide dental replica of two teeth prepared for complete crown with 10-degree convergence one represent canine and other represent molar with edentulous interposed space $42.1 \mathrm{~mm}$ $\{1\}$. Auto polymerized resin perforated custom tray with $2 \mathrm{~mm}$ spacer constructed from master cast $\{2\}$. The trays paints with adhesive, and allowed to dry for 60 seconds before obtaining the impressions $\{3\}$. Regular body vinylpolysilixane impression material (Elite HD+ regular body zhermack) used for fabrication of 30 impressions \{4\}. A 20 impressions act as control (10 of them left in atmosphere for 30, 60 minutes and other 10 immersed in distilled water for 30, 60 minutes before pouring). Other 10 impressions (test group) immersed in a glutaraldehyde disinfectant solution (MD 520 impression disinfection) for 30 and 60 minutes. All impression poured with extra hard dental stone. Obtained casts evaluated for linear dimensional changes using a digital caliper. Data tabulated and statistically analyzed using one-way analysis of variance with a significance level set at $=0.05$.
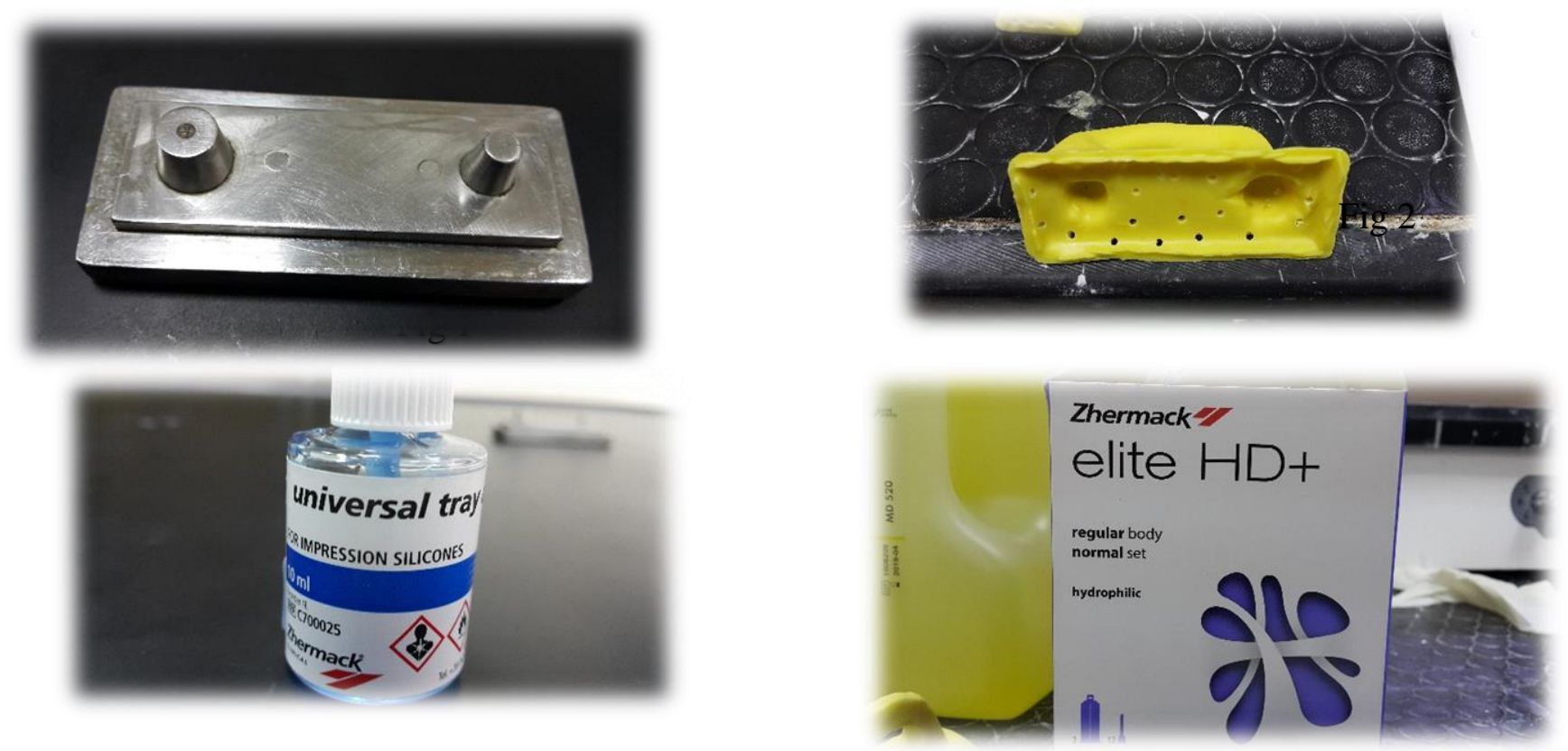

\section{Results:-}

The highest dimensional change value was recorded after immersion impressions in distilled water for 60 minutes while, the lowest value was recorded after immersion in disinfectant solution for 60 minutes. There is no significant difference in dimensional changes between control groups and test group at both immersion times.

\section{Stander model: $42.1 \mathrm{~mm}$}

\begin{tabular}{|l|l|l|l|l|l|l|}
\hline Group & A1 & A2 & B1 & B2 & C1 & C2 \\
\hline Time & 30 minutes & 60 minutes & 30 minutes & 60 minutes & 30 minutes & 60 minutes \\
\hline Sample 1 & 42 & 41.7 & 41.9 & 41.9 & 41.9 & 42 \\
\hline Sample 2 & 41.9 & 41.7 & 41.9 & 42 & 41.9 & 41.8 \\
\hline Sample 3 & 41.8 & 41.8 & 41.7 & 41.7 & 41.8 & 41.7 \\
\hline Sample 4 & 41.9 & 41.9 & 41.8 & 41.8 & 41.6 & 41.9 \\
\hline Sample 5 & 41.7 & 41.7 & 41.9 & 41.9 & 41.9 & 41.8 \\
\hline
\end{tabular}




\section{Dimentional changes in each group:}

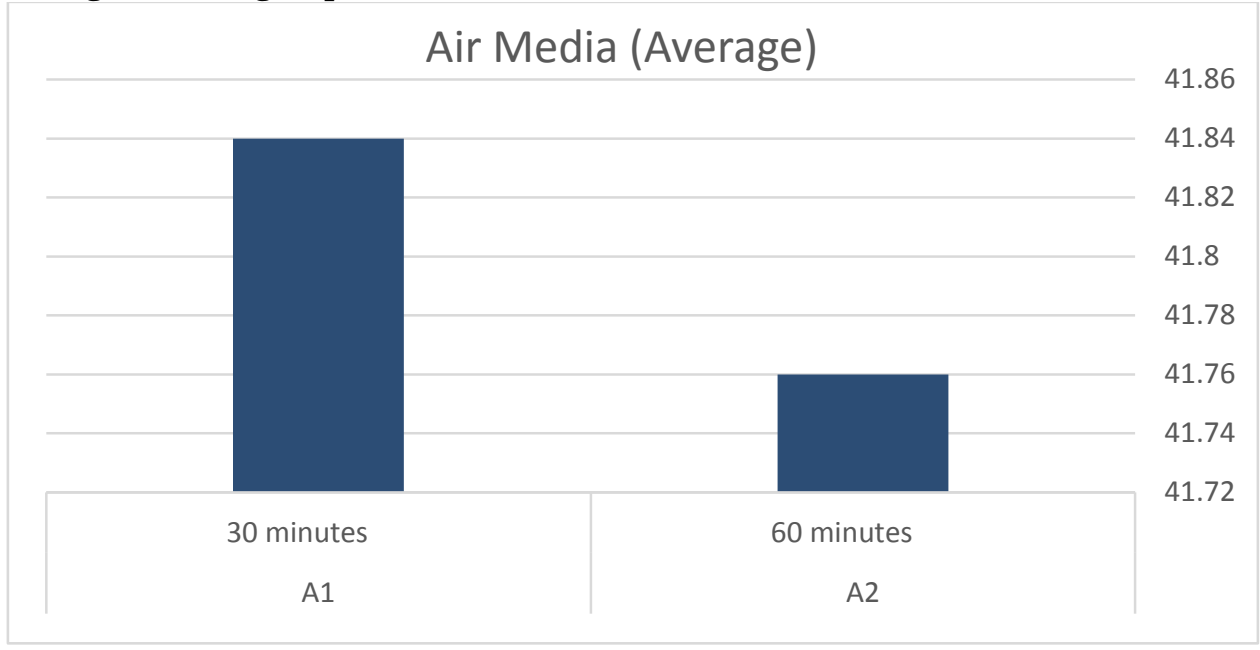

Water Media (Average)

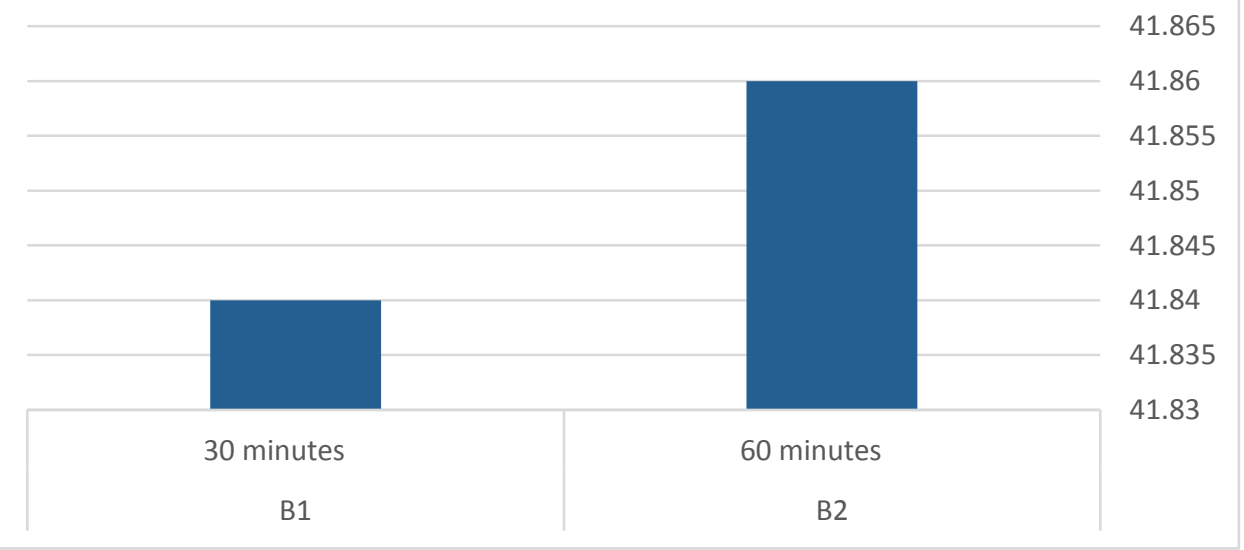

Disinfectant (Average)

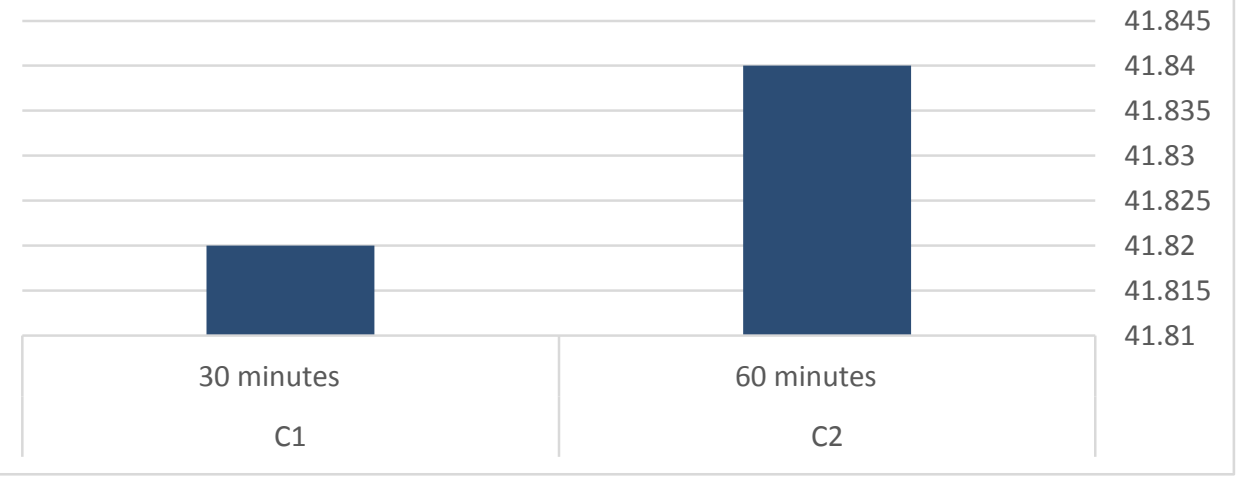




\section{Discussion:-}

Contamination of dental impression with alter amounts of blood and saliva is a routine incident in dental clinics therefore, every impression must be undergo surface disinfection treatments before further processing ${ }^{5}$. According to the information provided by the center of disease control, chemical disinfectants such as chlorine compounds, formaldehydes, glutaraldehydes, phenol and lodophers have the potential to destroy hepatitis, herpes and AIDS viruses in 10 to 30minutes. Also Through a questionnaire addressed to dental technicians, Jagger et al. found that only $4 \%$ of the laboratories received disinfected impressions, whereas $56 \%$ of the laboratories did not know if impressions coming from the dental offices had been previously disinfected. Therefore, most of the laboratories $(94 \%)$ usually disinfected the impressions they received ${ }^{6}$. This study evaluated and compared the dimensional changes of vinylpolysilixane impression material (Elite HD+ regular body zhermack) as a result of impression subjected to 3 defferent media ( air, water, disinfictant) at 30 and 60 minuts times immersion for each. We can see in the Air group (control) impressions left for 30 minuts more close to the standered dimension than the impression at 60 minuts by $(0.26 \mathrm{~mm})$.For water media the impression at 60 minutes was less than standered dimension by $(0.24 \mathrm{~mm})$. Finaly in disinfected media (glutaraldehyde disinfectant solution) the impression at 60 minuts less than stander dimension by $(0.026 \mathrm{~mm})$ and at 30 minuts by $(0.028 \mathrm{~mm})$. Chemical disinfection produced minimal dimensional changes compared to other two methods. Tullner et al observed no clinical significant dimensional changes with disinfection using $2 \%$ gluteraldehyde in his study.

\section{Conclusion:-}

Under the limitations of present study, tasted disinfection times (30 minutes \& 60 minutes) has no effect on dimensional accuracy of tested impression material.

\section{Reference:-}

1. Pritam P Lad1, Minal Gurjar2, Sachin Gunda3, Vivek Gurjar4, Nandan K Rao5. The Effect of Disinfectants and a Surface Wetting Agent on the Wettability of Elastomeric Impression Materials: An In Vitro Study. Journal of International Oral Health 2015; 7(6):80-83

2. Usama Nassar*, Carlos Flores-Mir, Giseon Heo, Ysidora Torrealba. The effect of prolonged storage and disinfection on the dimensional stability of 5 vinyl polyether silicone impression materials. J Adv Prosthodont 2017;9:182-7

3. Wala M. Amina, g, Muna H. Al-Alib, Sandra K. Al Tarawnehc, Sahar Th. Tahad,

4. Mohamed W. Salehe, Nadia Ereifij. The Effects of Disinfectants on Dimensional Accuracy and Surface Quality of Impression Materials and Gypsum Casts. J Clin Med Res • 2009: 1(2):81-89.

5. Usama Nassar, DDS, MS \& Ava K. Chow, RDH, PhD. Surface Detail Reproduction and Effect of Disinfectant and Long-Term Storage on the Dimensional Stability of a Novel Vinyl Polyether Silicone Impression Material. Journal of Prosthodontics 24 (2015) 494-498.

6. Matyas,N.Dao, A.A, Capto, F.M.Lucatorto: Effect of disinfectants on dimensional accuracy of impression materials J.prosthet.Dent. 1990; 64: 25-31. 